\title{
AS ESTRATÉGIAS TERRITORIAIS DAS EMPRESAS DE CONTACT CENTER: ESPECIALIZAÇÃO DOS SERVIÇOS PRESTADOS E A BUSCA POR NOVAS LOCALIZAÇÕES
}

\section{The territorial strategies of contact center companies: specialization of services provided and the search for new locations}

\author{
Marina Castro Almeida \\ Universidade de São Paulo, São Paulo, São Paulo, Brasil \\ mari.cas@ig.com.br
}

Artigo recebido em 28/01/2015 e aceito para publicação em 19/11/2015

RESUMO: $\quad$ Este artigo tem como objetivo analisar as estratégias territoriais das empresas de Contact Center. A especialização dos serviços prestados e a dispersão territorial para áreas mais vantajosas definiu a escolha das três empresas analisadas: Contax, Atento e a "Empresa A". As estratégias territoriais das duas primeiras expressam bem o que tem sido uma prática comum entre as grandes empresas do ramo: a dispersão das unidades produtivas para novas localidades, especialmente para a região Nordeste; articulada com a centralização do controle nas sedes corporativas, instaladas nas principais metrópoles brasileiras. Por outro lado, a "Empresa A" mantem a maior parte de suas unidades nas principais regiões metropolitanas do Sul e Sudeste, e, em oposição às demais firmas, concentra seus serviços em atividades mais especializadas, de tecnologia da informação e de infraestrutura de rede. Essas diferentes estratégias analisadas no artigo, decorrem, entretanto, de um objetivo comum: a busca por novas formas de acumulação, seja pela localização estratégica, seja pelo uso constante de novos sistemas informacionais.

Palavras-chaves: Divisão territorial do trabalho; empresas de Contact Center; estratégias territoriais; tecnologias da informação; incentivos territoriais.

ABSTRACT: The present article intents to analyze the spatial strategies of contact center companies. The specialization of services provided and the territorial dispersion for more advantageous areas set the choice of the three companies analyzed: Contax, Atento e a "Company A". The territorial strategies of the first two and express what has been a common practice among large sector companies: the dispersion of production units to new locations - especially for the Brazilian Northeast - made possible by the control at corporate headquarters, installed in the main Brazilian metropolis. On the other hand, the "Company A" keeps most of their units in the main metropolitan areas of South and Southeast, and, as opposed to other firms, concentrates his services in more specialized activities, as information technology and network infrastructure. These different strategies analyzed in the article, result, however, of a common goal: screening for new forms of accumulation, by the strategic location, or the constant use of new information systems.

Keywords: Territorial division of labor; territorial strategies; Contact Center companies; information technology; territorial incentives. 


\section{INTRODUÇÃO}

No dia 5 de novembro de 2013, a imprensa especializada nos serviços de atendimento anunciava os recentes acontecimentos: "Contax de olho no Acre". A reportagem dava conta de que a maior empresa de Contact Center do mercado brasileiro planejava a abertura de uma nova unidade na cidade de Rio Branco. O governador do estado, Tião Viana, recebeu na ocasião o diretor da Contax para negociar as contrapartidas pelos investimentos e pelos aclamados benefícios sociais decorrentes das novas instalações.

Apesar da aparente inversão na identificação dos favorecidos, os fatos condizem com o anúncio. O governador se comprometeu em negociar algumas compensações à empresa que, por sua vez, deveria avaliar se as ofertas eram ou não satisfatórias. Desse modo, a instalação de uma nova unidade em determinado local, com o objetivo de valorização do capital da empresa e de ampliação de sua acumulação, seria ainda acompanhada da concessão de benefícios pelo poder público.

Na realidade, a escolha das novas localizações pelas empresas é quase sempre orientada pelas vantagens comparativas, o que quer dizer que os pontos eleitos para a construção de novas unidades são os que apresentam, especialmente, os menores custos de produção. Além da mão de obra barata e considerada mais "comprometida" com a empresa, pelo fato de terem poucas opções de emprego, são ofertados pelo poder público uma série de benefícios territoriais (as denominadas "contrapartidas"), tais como: isenção de impostos, doação de terrenos e a construção de infraestruturas, quase sempre de uso exclusivo das empresas.

Esse episódio ilustra uma prática comum nas relações entre as empresas e o Estado, em seus diferentes níveis e esferas de governo. A dispersão territorial para áreas mais vantajosas, onde há concessão de benefícios, é uma importante estratégia territorial praticada pelas empresas de Contact Center no mercado brasileiro.

Todavia, outro exemplo, menos recorrente, e que será analisado neste artigo pela sua peculiaridade, é o caso da "Empresa A" (cujo nome será ocultado por exigência de sigilo quanto à identificação dos dados primários obtidos em trabalho de campo), que concentra suas atividades na metrópole de São Paulo e em outras regiões metropolitanas do Sul e Sudeste, apesar do custo relativamente alto dos imóveis e da mão de obra nessas áreas. Esse fato decorre de sua estratégia centrada na prestação de serviços especializados, que exige mão de obra qualificada - como os trabalhadores vinculados à tecnologia da informação (TI)- e a proximidade com as empresasclientes para a gestão dos negócios.

A partir da análise das diferentes estratégias territoriais de algumas empresas de Contact Center, este artigo busca responder algumas importantes questões: quais são as diferentes estratégias territoriais alçadas pelas empresas para ampliação de sua acumulação? Como essas estratégias se expressam na sua divisão territorial do trabalho? Quais são os sistemas técnicos que viabilizam tanto a especialização dos serviços prestados, como a aceleração do capital (com a efetivação de um número maior de chamadas por minuto, por exemplo), ou ainda a dispersão territorial das unidades produtivas?

Para isso, o artigo está dividido em duas partes. A primeira contém dois subitens sobre a tipologia das empresas de Contact Center e dos serviços por elas prestados. No que se refere à tipologia das empresas, buscou-se analisar a transformação das antigas centrais de atendimento nos atuais Contact Centers, a partir da utilização de novos sistemas técnicos nas operações. Com isso, a flexibilidade locacional e a manipulação de complexos bancos de dados se tornaram estratégias centrais na gestão territorial das empresas.

No que concerne à tipologia dos serviços prestados, foi fundamental a elucidação acerca da origem e da trajetória dos Contact Centers. A maior parte deles surgiu no interior de outras empresas para atender às exigências do Código de Defesa do Consumidor, criado em 1990, que regulamentou o Serviço de Atendimento ao Consumidor (SAC). Posteriormente, sua função ultrapassou as exigências normativas de fornecimento de informações sobre os produtos e serviços prestados. O que antes era visto como custo para as empesas alcançou um papel relevante como um novo meio de acumulação, a partir do uso das informações dos clientes e como possibilidade de oferecimento de novos serviços. 
Desse modo, além dos serviços de atendimento aos consumidores, os Contact Centers passaram a agregar o planejamento e a gestão dos negócios das empresasclientes.

A segunda parte do artigo analisa a divisão territorial de três empresas de Contact Center: Contax, Atento e a "Empresa A". A escolha dessas empresas se justifica pela intenção de demonstrar como o uso das inovações tecnológicas permite a ampliação do lucro das empresas por duas vias distintas. A primeira é o uso da tecnologia para viabilizar o comando das operações dispersas territorialmente. Assim, a escolha das empresas Contax e Atento tem como objetivo analisar a recente dispersão territorial de suas unidades produtivas amparada pela centralização do controle (nas sedes corporativas) nas principais metrópoles brasileiras.

A segunda forma utilizada pelas empresas para o aumento dos lucros é o uso de inovações tecnológicas na prestação de serviços mais especializados. Um exemplo dessa prática são as estratégias da "Empresa A", que representa uma exceção no mercado brasileiro de Contact Center. Sua especificidade decorre da prestação de serviços de tecnologia da informação (TI) e por atuar em atividades de maior valor agregado, associadas à gestão de infraestrutura informacional das empresas-clientes e ao planejamento de operações financeiras.

Por fim, uma advertência teórica. A ampliação da acumulação pelo uso das tecnologias da informação não é independente da busca por novas localizações, assim como nos esclarece Harvey (2006a [1982], p. 393). Para o autor, quanto mais a produção se aproxima de alguma condição de equilíbrio espacial, isto é, de equalização da taxa de lucro, maior o incentivo aos capitalistas individuais para buscarem novas condições (tecnológicas e locacionais) para a ampliação de sua acumulação, como será demonstrado a partir da análise das três empresas selecionadas.

\section{TIPOLOGIADAS EMPRESAS E DOS SERVIÇOS PRESTADOS}

\section{Das centrais de atendimento aos Contact Centers}

Inicialmente, os atuais Contact Centers eram denominados de centrais de atendimento, pois suas funções restringiam-se a operações mais simples, associadas à solução de dúvidas e às reclamações dos consumidores. Entretanto, o desenvolvimento das novas tecnologias da informação e da comunicação fez com que as centrais agregassem um número ainda maior de serviços, com o uso de mídias diversas, passando a ser denominadas Contact Centers.

O novo termo designa locais que, além de realizarem os serviços tradicionais de telemarketing, concentram ainda um número maior de informações sobre os consumidores (renda, periodicidade e tipologia das compras, local de residência, faixa etária, escolaridade, etc.). Os novos métodos de gestão da informação permitem a manipulação de bancos de dados cada vez mais complexos, capazes de cruzar preferências e traçar o perfil do potencial consumidor, adequando-se ao novo regime de acumulação flexível (HARVEY, 1996; BENKO, 1999).

O aumento da produtividade e a maior eficiência dos Contact Centers estão associados ao uso de determinados sistemas técnicos, tais como o Distribuidor Automático de Chamadas (DAC); a "Telefonia Integrada ao Computador", denominada de Computer-Integrated Telephony (CTI) e, especialmente, o VOIP, Voz Sobre Protocolo de Internet (sigla em inglês).

O DAC é um sistema telefônico que permite o atendimento automático das chamadas e a organização de filas. Quando o cliente faz a ligação, o DAC pode encaminhá-la para um operador disponível, para uma fila de espera ou ainda para uma Unidade de Resposta Audível (analisada a seguir). Com isso, as chamadas têm menos chances de receberem sinal de "ocupado", o que evita que o usuário desista da ligação.

A integração do DAC com outros componentes, como os gerenciadores PABX (sigla em inglês para troca automática de ramais privados), permite o transbordo das chamadas para outros ramais, inclusive para unidades da empresa instaladas em outro município. O DAC permite classificar os clientes a partir de critérios pré-estabelecidos. Com isso, é possível dar prioridade aos clientes mais importantes, o que pode ser feito em todos os canais utilizados: nas chamadas telefônicas, por e-mail ou chat, e nos atendimentos via Web. O DAC também registra o histórico de dados e atendimentos, além da geração de relatórios. 
A Unidade de Resposta Audível (URA) é o aparelho que permite o encaminhamento automático da chamada e o autoatendimento a partir de menus de opções. Quando a ligação é encaminhada para o operador, ele dispõe de todas as informações do cliente na tela de seu computador, fornecidas no pré-atendimento e pelo histórico registrado. A oferta do serviço ou do produto mais adequado a cada situação é guiada por bancos de dados integrados ao sistema de telefonia. Trata-se da tecnologia CTI (Telefonia Integrada ao Computador, tradução da sigla em inglês), que permite integrar uma rede telefônica a terminais de computadores ligados em rede e controlados por softwares específicos para as operações de Contact Center.

$\mathrm{O}$ acesso privilegiado a estes sistemas técnicos permite às grandes empresas o uso das vantagens locacionais e a ampliação da acumulação. A associação entre o distribuir de chamadas (DAC) e o uso da tecnologia VOIP é revolucionária do ponto de vista organizacional. O VOIP consiste na digitalização da voz e sua transmissão em pacotes de dados (comutação por pacotes) via Internet.

Além de diminuir os custos com ligações e infraestruturas, o VOIP permite a dispersão territorial dos atendentes, mantendo a centralização do controle. Essa tecnologia integra, numa mesma chamada, operadores de diferentes locais (inclusive em outros países), sem que o cliente perceba. Aplicada ao teleatendimento, o VOIP amplia as estratégias corporativas. As empresas podem contratar operadores que realizam suas atividades de sua própria casa (home agent) ou ainda manter centrais de atendimento distribuídas em diferentes países, realizando serviços escalonados de acordo com sua complexidade. Dessa forma, elas podem minimizar os custos com infraestrutura, mão de obra e deslocamentos, sem deixar de acompanhar de maneira remota o trabalho executado (PINHO; VARGENS, 2005).

Assim, o VOIP e as tecnologias a ele associadas proporcionam a redução dos custos das operações e a aceleração da circulação do capital. Em 2011, enquanto o preço médio da telefonia fixa (comutação por circuitos) era de $\mathrm{R} \$ 0,67$ por minuto, no sistema VOIP era de apenas $\mathrm{R} \$ 0,17$, isto é, uma redução de $75 \%$ no custo das ligações das empresas (NOREMBERG; MÜLLER, 2011). No que se refere à velocidade de circulação do capital, o uso desses sistemas técnicos permite a realização de ligações simultâneas e a diminuição do intervalo entre as chamadas. A Figura 1 apresenta o funcionamento do Contact Center e a distribuição das chamadas acompanhadas do acesso aos bancos de dados.

Figura 1 - Funcionamento do Contact Center

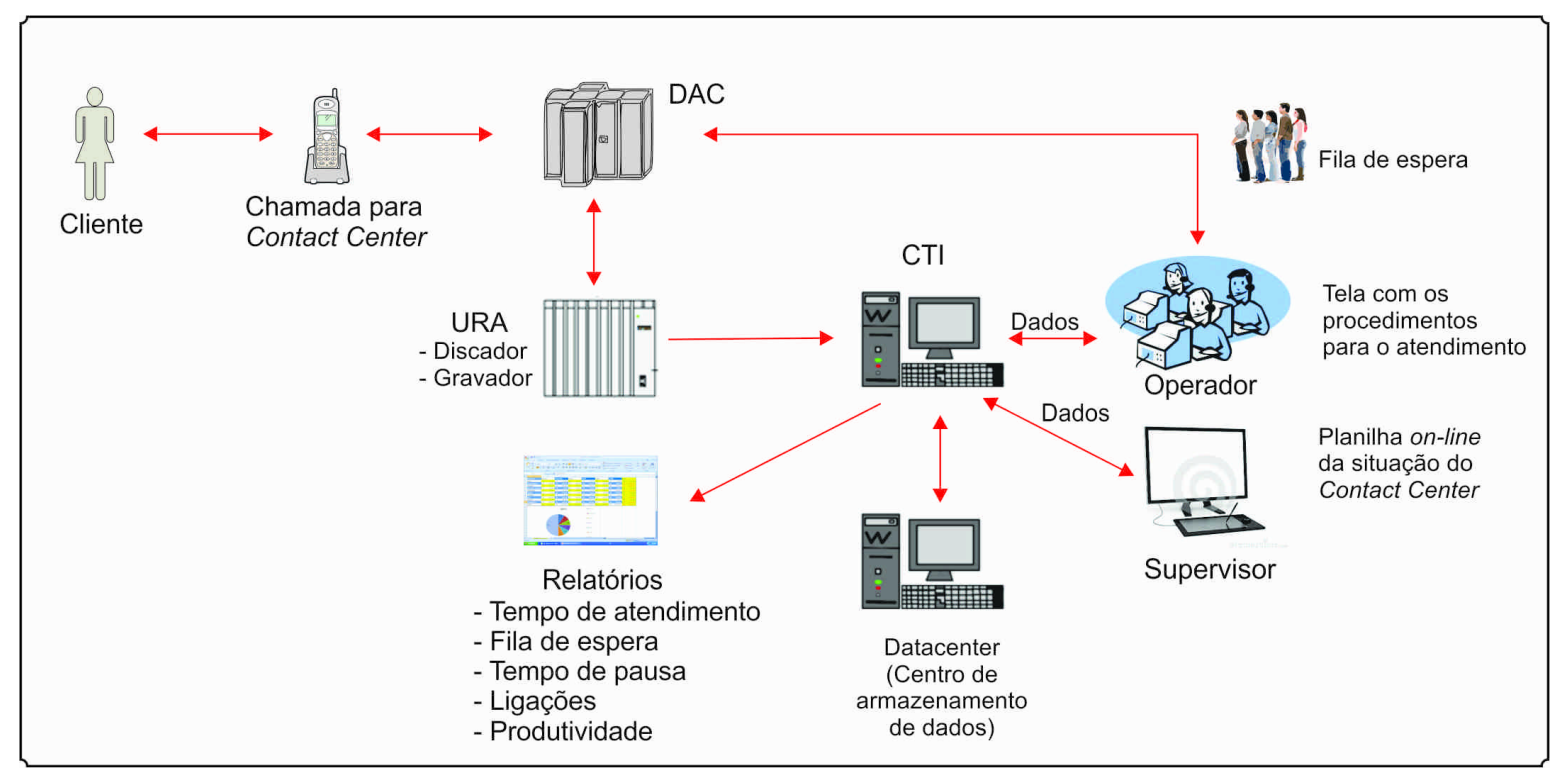

Fonte: Elaboração própria 
A centralização dos dados e, principalmente, a combinação de ferramentas para o acesso ágil e eficiente a todas as informações estão entre as principais funções desempenhadas pelos softwares de Customer Relationship Management (CRM), isto é, de gestão de relacionamento com o cliente. Além do registro e do tratamento das informações, o CRM permite separar os contatos por tipos de clientes ou de fornecedores e, especialmente, organizar e expor todas as informações de forma simples e visível durante os atendimentos.

A autonomia locacional é usada como uma vantagem competitiva para as empresas, tanto para as atividades desenvolvidas no território brasileiro, quanto para a exportação do atendimento, o offshore. A redistribuição territorial dos serviços é uma estratégia audaciosa, pois permite manter grupos de trabalhadores disseminados pelo globo, segundo as vantagens comparativas de cada lugar.

Com isso, as operações de teleatendimento que antes eram restritas ao final de um processo, ou seja, à solução de problemas e reclamações, à fidelização do cliente ou à realização de uma venda, ganharam novas atribuições. A informação se tornou a matériaprima e a fonte de energia para o funcionamento dos Contact Centers, que além de produzi-las passaram a comercializá-las por meio de serviços de consultorias, planejamento de campanhas publicitárias, pesquisas de mercado e gerenciamento logístico.

\section{Os serviços prestados pelos Contact Centers}

Apesar dos serviços de teleatendimento manterem uma estreita ligação entre si e dependerem de uma complexa infraestrutura para o compartilhamento dos dados, é possível dividi-los em três grupos: o teleatendimento em geral; vendas; e atividades de TI, associadas ao fornecimento e à manutenção de infraestrutura tecnológica e à gestão dos negócios das empresas-clientes.

Dentre o teleatendimento em geral, além das tradicionais abordagens de atenção ao consumidor (informação e reclamação), as políticas de fidelização e de retenção representam também alguns exemplos de como as empresas se apropriaram da estrutura das centrais telefônicas para elevar ao máximo seus benefícios. Como o custo para angariar novos clientes e convencê-los a adquirir um novo produto é mais elevado do que ampliar o lucro advindo de um cliente frequente, o objetivo das políticas de fidelização e retenção é "fortalecer o relacionamento com os consumidores", ou seja, aumentar o percentual de participação de cada cliente.

A intensificação da comunicação com o consumidor visa, portanto, a oferta de produtos e serviços, ainda que associada ou disfarçada de assistência ou de "proteção ao consumidor". O contato pós-venda, para aferir a satisfação dos consumidores, por exemplo, é utilizado para a oferta de novos produtos. Os artifícios para a retenção e a fidelização dos clientes são geralmente guiados pelas informações obtidas com as compras anteriores, capazes de identificar o potencial para novos negócios.

Ainda no âmbito dos serviços de atendimento, há algumas inovações na prestação do suporte técnico. As empresas utilizam os contatos para fornecer informações para a instalação de produtos ou resolução de problemas e, recentemente, tem se intensificado a prestação de serviços mais especializados. Para tanto, os Contact Centers passaram a contratar profissionais com formações específicas, tais como: técnicos em TI, para assessorar nas atualizações de softwares; e médicos, nas operações que prestam serviços às seguradoras de saúde.

Com relação aos "serviços orientados à venda", a mundialização de um sistema técnico hegemônico e a possibilidade de produção e gerenciamento das informações corporativas permitiram às empresas a otimização de determinadas atividades, sobretudo, das campanhas de vendas. Estas passaram a ser feitas a partir da seleção dos clientes potenciais, escolhidos com base no cruzamento de bancos de dados detalhados que indicam as melhores estratégias de marketing. Como relatado anteriormente, as formas de abordagem são definidas de acordo com o perfil do consumidor traçado a partir da análise de informações coletadas pelo histórico de contatos ou compradas de empresas de consultoria.

Alguns contratos de terceirização extrapolam a prestação de serviços de teleatendimento ou de venda e integram atividades mais complexas, associadas à "gestão dos negócios das empresas- 
clientes". Dentre as atividades, destacam-se o Business Process Outsourcing (BPO) e o Business-to-business (gestão do relacionamento com os demais agentes corporativos).

A terceirização de Processos do Negócio ou BPO é uma estratégia utilizada pelas grandes empresas para a redução dos custos trabalhistas e operacionais por meio da subcontratação. As atividades transferidas para as empresas terceiras envolvem diversos serviços como: atendimento ao consumidor, contabilidade, folha de pagamento, atividades fiscais e financeiras, cobrança, recrutamento e seleção e treinamento da mão de obra. Os processos terceirizados dependem do grau de integração entre a empresa-cliente e a terceirizadora. Em alguns casos é delegada apenas a gestão de bancos de dados de clientes ativos, para a seleção dos contratos mais lucrativos e a definição de estratégias de marketing. Em outras situações, há a terceirização da auditoria, da estrutura logística e da criação e manutenção dos softwares e das plataformas informacionais.

O que ocorre, portanto, é o aumento da prestação de serviços intermediários, com a transferência de atividades que antes eram realizadas pela própria empresa. Vale ressaltar que os novos serviços oferecidos só são possíveis graças ao desenvolvimento de um sistema unificado de técnicas instalado sobre um planeta informado, que permite ações igualmente globais (SANTOS, 2000). Apenas as grandes empresas podem usufruir plenamente das vantagens competitivas alcançadas pela convergência tecnológica inerente aos novos serviços.

\section{DIVISÃO TERRITORIAL DO TRABALHO DAS EMPRESAS DE CONTACT CENTER}

O atual período da globalização, caracterizado pela associação entre as técnicas da informação (SANTOS, 1996; LOJKINE, 1995), as políticas neoliberais (PECK; TICKEL, 2002) e a financeirização da economia (HARVEY, 2004; ARRIGHI, 1996; CHESNAIS, 1996), é o contexto em que se expandiram as atividades de Contact Center no território brasileiro. A adoção, ainda que parcial, das diretrizes do Consenso de Washington, na década de 1990 (FIORI, 2001) promoveu, dentre outros eventos, a privatização de empresas estatais e a internalização de grandes corporações transnacionais. O sistema estatal de telecomunicações brasileiro, criado no início da década de 1970 (DIAS, 1995; 2005), foi adquirido quase que exclusivamente por corporações estrangeiras, abrindo novas possibilidades de acumulação para essas empresas (HARVEY, 2010).

Para o setor de telecomunicações, o neoliberalismo não representou apenas a chegada de empresas estrangeiras, mas, sobretudo, a abertura de um novo mercado. Após as privatizações, as novas controladoras do sistema telefônico brasileiro criaram empresas especializadas nos serviços de teleatendimento (Contact Center), com o objetivo de reduzir seus custos de produção. A criação dos Contact Centers, ao mesmo tempo em que desobrigou as teles das despesas com a mão de obra, impulsionou também o surgimento de novos serviços, assim como analisado na sessão anterior.

As três empresas aqui analisadas (Contax, Atento e "Empresa A") surgiram nesse contexto de hegemonia da ideologia e das políticas neoliberais (PECK; TICKEL, 2002, p. 384). As duas primeiras foram criadas como empresas subsidiárias das companhias telefônicas privatizadas no final da década de 1990. Já a "Empresa A" teve origem em 2005 a partir da fusão de duas empresas da área de terceirização de processos de negócios (na sigla em inglês BPO). Desde 2009 a empresa tem sido controlada por fundos de investimentos financeiros, $\mathrm{o}$ que reflete também uma característica do atual período do capitalismo globalizado, isto é, a financeirização da economia (HARVEY, 2004; ARRIGHI, 1996). Da mesma maneira como ocorre em outros setores, a aquisição de empresas de Contact Center por fundos financeiros representa a ampliação das possibilidades de acumulação para um pequeno grupo de especuladores.

Essa empresa se caracteriza pela prestação de serviços de consultoria em tecnologia da informação. Ao contrário da maior parte das empresas de Contact Center instaladas no Brasil, dedicadas a serviços menos complexos, a prestação de serviços de TI é uma atividade de maior valor agregado e realizada por trabalhadores mais qualificados. Esses serviços estão associados a rendimentos muito superiores 
quando comparados às atividades de atendimento ou orientadas à venda.

Já a Atento e a Contax, que juntas controlam quase $50 \%$ do mercado de teleatendimento brasileiro, direcionam sua estratégia principalmente para a prestação de serviços padronizados, de baixa complexidade e com ganhos em escala. No geral, elas concentram suas atividades em poucos clientes - a maior parte da receita decorre dos serviços prestados à Telefônica e à Telemar, respectivamente -, e prestam serviços de baixo valor agregado, o que permite a diminuição dos custos unitários de operação.

\section{Divisão territorial do trabalho da "Empresa A" $e$ os} serviços de TI

A divisão territorial do trabalho da "Empresa A" demonstra como os investimentos em tecnologia da informação e a prestação de serviços com maior valor agregado estão associados à manutenção de unidades de produção de tecnologia em lugares estratégicos, capazes de viabilizar a comunicação dos dados corporativos.

Como apresentado na Figura 2, a empresa mantém sua sede em Mogi das Cruzes (SP); os datacenters em São Paulo (SP), São José dos Campos (SP) e Rio de Janeiro (RJ); as fábricas de softwares nas três cidades anteriores e Curitiba (PR); e as operações de teleatendimento em outras oito cidades. No total, a empresa possuía, em 2011, pouco mais de 23 mil funcionários nas centrais de teleatendimento (Contact Centers), quase dois mil nos datacenters e em torno de 600 nas fábricas de softwares.

Figura 2- Divisão Territorial do trabalho da "Empresa A", 2011

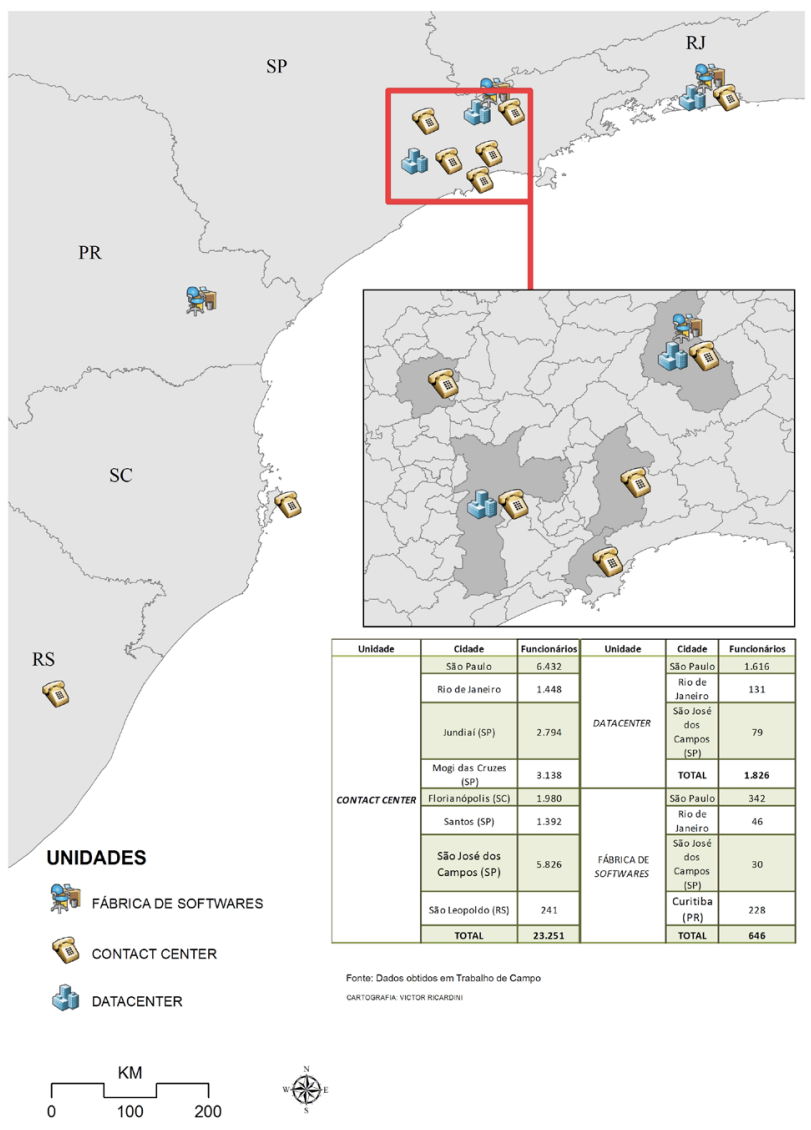

Fonte: Elaboração própria 
Os três datacenters, especialmente, o de São Paulo, pelo maior número de funcionários, centralizam os dados e informações para o comando das ações de todas as demais unidades produtivas (Contact Centers e Fábrica de Softwares). Nas fábricas de softwares, a empresa realiza a fabricação e a adaptação de programas de computadores para atender às operações de cartões de crédito, débito ou pré-pago, além de todo sistema de cobranças, como a venda, o processamento e a liquidação financeira das transações.

As operações realizadas nas centrais de atendimento são viabilizadas pelos sistemas de informação e programas de computadores produzidos nas fábricas de softwares e apoiadas pelos dados armazenados nos datacenters. A mão de obra empregada nas unidades de desenvolvimento de tecnologia (fábricas de softwares e datacenters) é especializada, com maior qualificação (geralmente analistas em TI e consultores) e em quantidade bem inferior, se comparada com as centrais de atendimento.

Devido ao elevado contingente de trabalhadores e de contatos realizados, os Contact Centers possuem grande dependência dos sistemas de transporte e das redes telemáticas. O estado de São Paulo concentra o maior número de centrais de atendimento. As cidades de São Paulo, São José dos Campos e Mogi das Cruzes concentram mais de 15 mil funcionários, $66 \%$ do total dos operadores da empresa. Nos demais estados, a cidade de Palhoça (SC), na Região Metropolitana de Florianópolis (SC), se destaca com quase dois mil funcionários, seguida pela capital fluminense e pela cidade de São Leopoldo (RS), na Região Metropolitana de Porto Alegre (RS).

Na cidade de São Paulo, as unidades de TI (fábrica de softwares e datacenters) localizam-se no chamado centro de negócios (CORDEIRO, 1980), na Avenida Brigadeiro Faria Lima. Os edifícios são equipados com uma série de aparatos tecnológicos que atendem à demanda de rapidez e fluidez do grande capital (CASTILLO; SILVA, 2007). As modernas instalações possuem pisos elevados que facilitam a conexão dos cabos e o controle da temperatura. Além de contarem também com zonas de refrigeração para o resfriamento dos equipamentos capazes de armazenar e processar enorme quantidade de dados, e um sistema de geradores de energia que permite autonomia em casos de falha no fornecimento pelo sistema público.

A "Empresa A" concentra $84 \%$ de seus funcionários de produção de tecnologia e de gerenciamento de dados num raio de $100 \mathrm{~km}$ a partir da cidade de São Paulo. As cidades de São José dos Campos e Mogi das Cruzes são locais estratégicos para a gestão superior dos negócios da empresa, o que enfatiza o caráter metropolitano dessa área do território paulista (LENCIONI, 2003). A sua divisão territorial do trabalho substantiva a noção proposta pela autora de "metropolização do espaço", isto é, de que a dinâmica metropolitana transcende a cidade de São Paulo, englobando também regiões adjacentes, como o caso do datacenter instalado na cidade de São José dos Campos.

Entretanto, como assevera Lencioni (2003, p. 6), não há uma "absolutização do processo homogeneizador", ou seja, a metropolização não alcança plenamente todos os lugares e, acrescentamos, tampouco todos os indivíduos. De forma contraditória, o uso corporativo do território ao mesmo tempo em que integra determinados pontos à economia globalizada, fragmenta e exclui áreas adjacentes. As disparidades se intensificam também no mundo do trabalho, já que para cada funcionário empregado nas unidades de produção de tecnologia da "Empresa A", há mais de nove operadores nas centrais de atendimento e tantos outros como "exército de reserva".

\section{Divisão territorial do trabalho e os serviços prestados pelas empresas Atento e Contax}

Como destacado anteriormente, ao contrário da "Empresa A", a maioria das empresas de Contact Center brasileiras não atua na gestão e desenvolvimento de TI, restringindo-se à prestação de serviços menos qualificados, como o atendimento aos consumidores.

Este fato decorre da origem das empresas brasileiras de Contact Center estar associada à redução dos custos trabalhistas das companhias telefônicas pela terceirização dos serviços de atendimento. Dessa forma, as empresas de Contact Center mantiveram suas atividades concentradas em poucas empresas-cliente e na prestação de serviços de baixo valor agregado. 
As empresas Contax e Atento são os melhores exemplos da situação descrita. Ambas surgiram como subsidiárias de companhias telefônicas após as privatizações, como ressaltado anteriormente.

No que se refere à capacidade produtiva, enquanto a "Empresa A" possuía, em 2013, uma estrutura com 12 mil posições de atendimento (PAs) e prestava grande diversidade de serviços de TI e de consultoria, a Atento e a Contax, tinham 36 mil e 48 mil PAs, respectivamente, e concentravam suas receitas em contratos de grande volume e de baixo valor agregado - a maior parte deles prestados para suas controladoras, a Telefônica e a Telemar.

A Figura 3 apresenta a evolução no número de PAs das empresas Atento, Contax e Empresa A entre 1999 e 2013, e demonstra como as duas primeiras, em períodos distintos, expandiram suas estruturas produtivas.

Figura 3 - Crescimento no número de PAs das empresas Atento, Contax e "Empresa A", 1999-2013

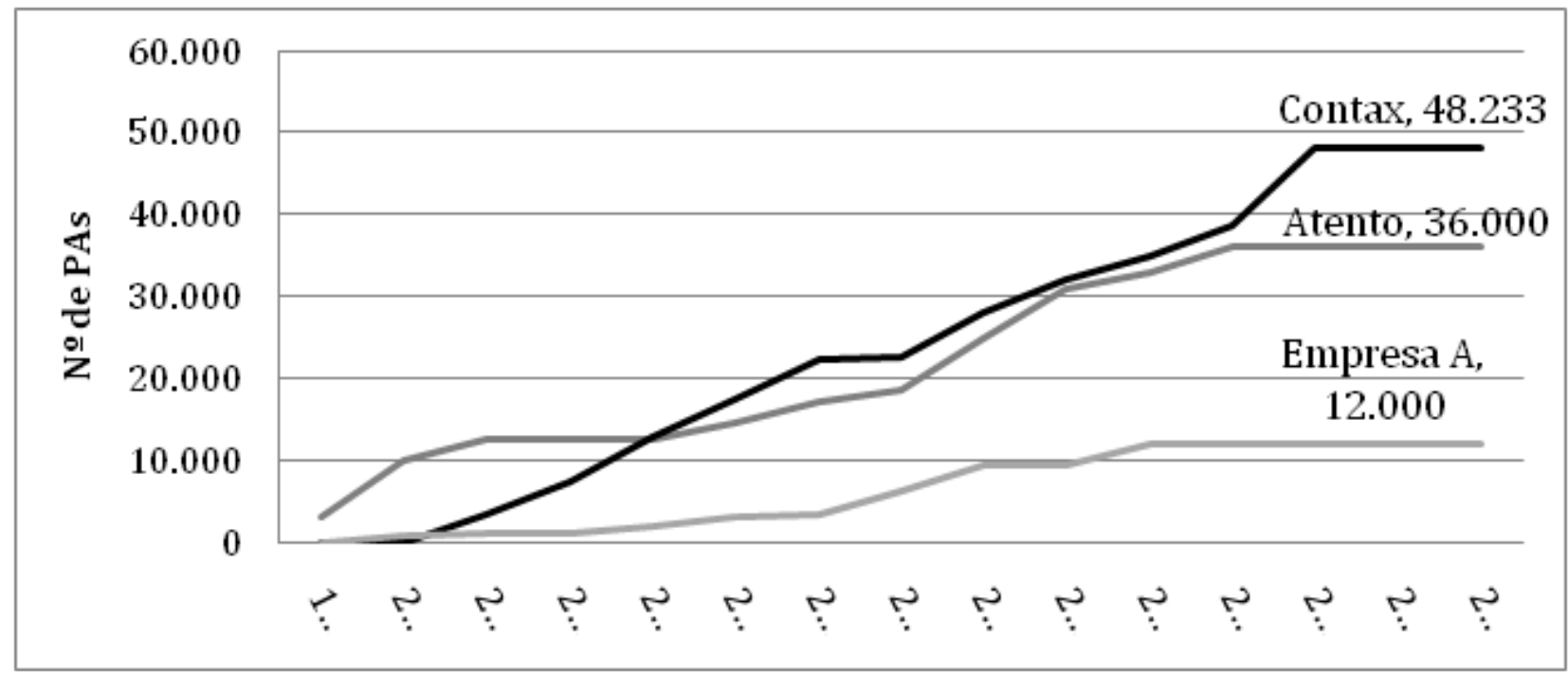

Fonte: callcenter.inf.br, 2013

Em 1999, logo após a sua entrada no mercado, a Atento adquiriu a Trilha, empresa baiana que detinha 580 PAs instaladas em Salvador (SILVA NETO, 2005, p. 178). Porém, a compra da empresa Quatro/A, segunda maior entre as terceirizadas brasileiras em 2000, foi o fato mais relevante para explicar o crescimento de mais de $300 \%$ em seus dois primeiros anos de operação no território brasileiro. Nos anos seguintes, entre 2001 e 2003, a Atento estabilizou seu crescimento, enquanto a Contax expandiu significativamente sua capacidade produtiva, tornando-se líder do mercado a partir de 2004. Essa rápida expansão ocorreu com a obtenção de importantes clientes como a Xerox e o Banco Panamericano e, em particular, com a aquisição de duas mil PAs das centrais de atendimento da empresa
Orbitall, do grupo Credicard.

De forma diferente, a estrutura produtiva da "Empresa A" é significativamente menor, como visto anteriormente, e o crescimento no número de PAs no período analisado também foi muito inferior quando comparado às outras duas empresas. Enquanto a Atento e a Contax possuem contratos de grande volume e com ganhos em escala, a "Empresa A" presta serviços com maior valor agregado. A Figura 4 mostra a distribuição dos 30 sites da empresa Atento e o número de operadores. 
Figura 4 - Distribuição e número de operadores da empresa Atento, 2011

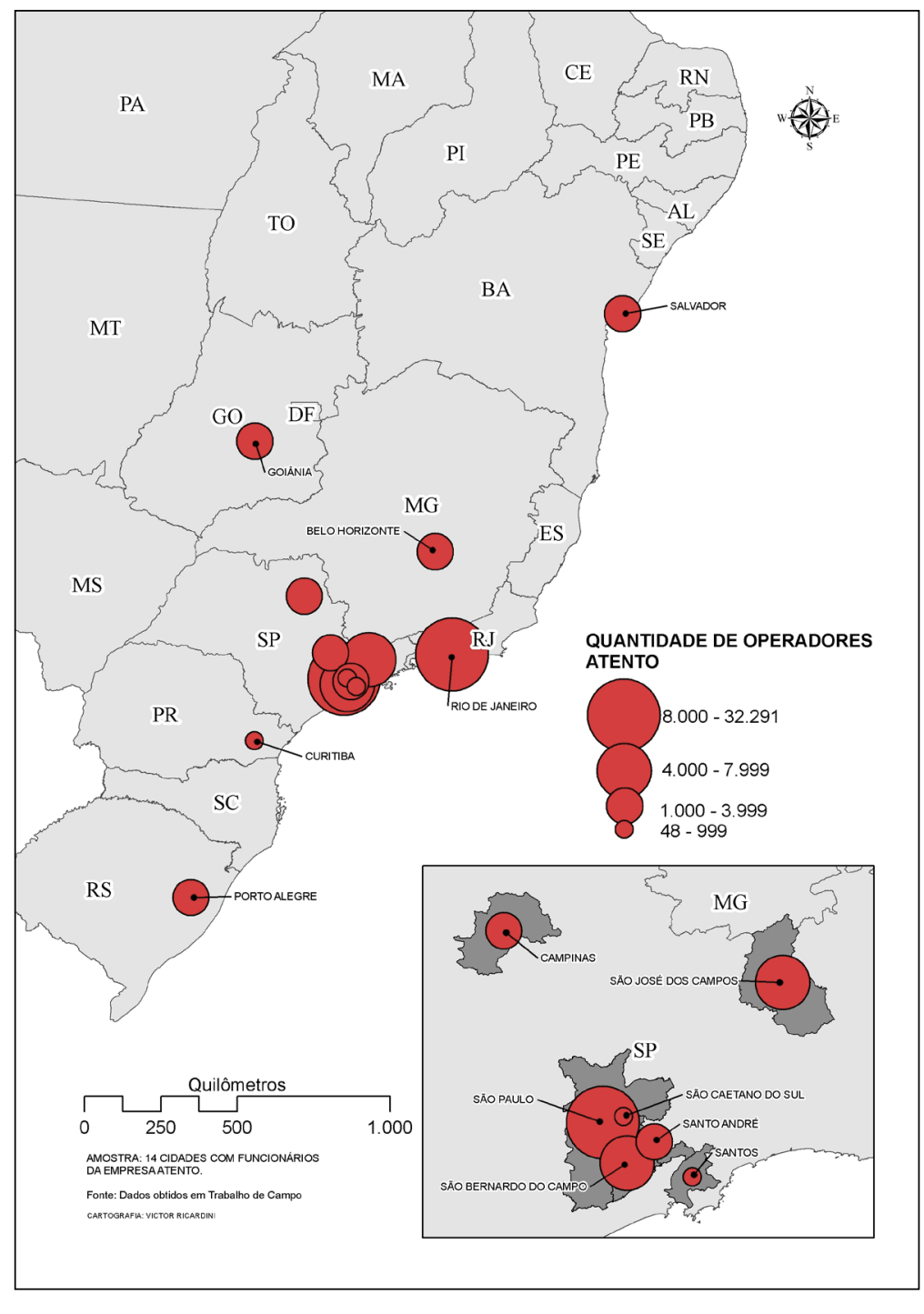

Fonte: Elaboração própria

A região Sudeste concentrava em 2011, 88\% dos operadores da Atento, e o estado de São Paulo sozinho empregava cerca de 50 mil funcionários, distribuídos em 20 centrais de atendimento. Os dois sites localizados em Salvador (BA) representavam apenas $4,5 \%$ do total de operadores da empresa. Além de percentualmente pouco relevantes, as duas únicas unidades instaladas na região Nordeste não resultam das estratégias recentes de expansão da empresa. Elas foram adquiridas em 1999, com a compra da empresa Trilha.

A estratégia organizacional da empresa para a ampliação da acumulação tem sido o compartilhamento da infraestrutura tecnológica entre as antigas unidades e as recém-construídas. As duas últimas unidades da Atento construídas na cidade de São Paulo, nos bairros do Limão (em 2008) e de Santo Amaro (em 2009), utilizam tecnologia remota instalada na antiga central de atendimento no bairro do Belém. Com isso, a construção dos novos sites de operação tem um custo reduzido, já que toda a infraestrutura tecnológica é compartilhada entre suas três unidades, como: os sistemas técnicos utilizados para gerenciar o fluxo de chamadas, para fornecer informações sobre os clientes e para realizar gravações dos atendimentos.

Com o compartilhamento dos sistemas 
técnicos, a Atento conseguiu se apropriar das vantagens de se localizar na metrópole de São Paulo sem ter de pagar o elevado custo de implantação de tecnologia para gerenciamento das informações. Dentre as vantagens destacam-se: a oferta de mão de obra e a proximidade com as demais empresas-cliente.

Em 2012, a Atento inaugurou um site com 2,2 mil PAs e capacidade para cinco mil trabalhadores na cidade do Rio de Janeiro. A construção dessa central de atendimento na Zona Norte da cidade é um importante exemplo de cooperação do Estado para o uso privilegiado do território por alguns agentes hegemônicos. A presença da Presidente da República e do Governador do Estado na inauguração da nova unidade e o discurso que associa a empresa à geração de emprego e à revitalização urbana comprovam a tentativa de defesa de um projeto pensado apenas para uma parte da nação, mas, que tem sido apresentado como benéfico para todos.

A Lei 5.044, sancionada pelo Prefeito do Rio de Janeiro, em junho de 2009, incentiva a criação de um Polo Nacional de Call Center nas regiões Norte e Oeste da cidade. O Projeto, aprovado por unanimidade pela Câmara Municipal, institui a redução da alíquota de Imposto Sobre Serviços (ISS) de 5\% para 2\% e a isenção do Imposto Sobre a Transmissão de Bens Imóveis (ITBI) e do Imposto Predial e Territorial Urbano (IPTU) por três anos consecutivos.

Os fatos corroboram com a posição defendida por Hirst e Thompson (1998) de que apesar da retórica da globalização, o mercado, como forma de regulação, não basta a si mesmo e não prescinde do apoio do Estado. A solidariedade às ações das grandes empresas vai além dos incentivos fiscais. Há ainda a instalação e a garantia do uso privilegiado das redes de comunicação e de transporte, as políticas educacionais voltadas para formação profissional especializada e, principalmente, a eloquência de um discurso em defesa das corporações.

Diferente da Atento, que privilegiou a instalação de unidades nas grandes metrópoles do Sudeste, a empresa Contax tem instalado suas novas centrais de atendimento, sobretudo, na região Nordeste e em outros países sul-americanos. A figura a seguir apresenta a divisão territorial do trabalho da empresa.

Figura 5 - Distribuição e número de operadores da empresa Contax, 2013

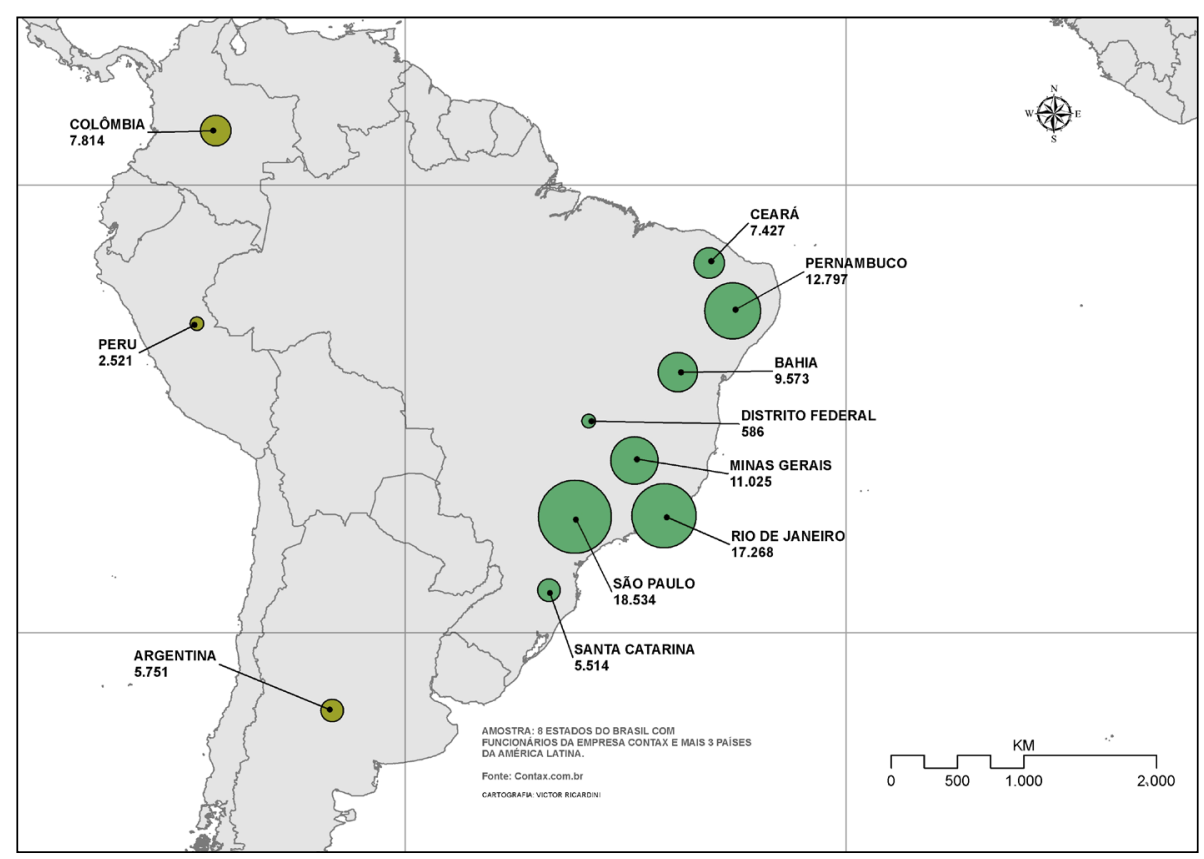

Fonte: Elaboração própria 
Com a incorporação da empresa Allus, em 2011, a Contax passou a operar também em outros países sul-americanos, como Argentina, Colômbia e Peru. No total, a empresa possui cerca de 50 centrais de atendimento localizadas em oito estados brasileiros, no Distrito Federal e em cidades dos países anteriormente mencionados: Córdoba e Mendonza, na Argentina; Bogotá e Medellín, na Colômbia; e em Lima, no Peru.

No Brasil, a empresa possui nove unidades na região Nordeste, com cerca 30 mil funcionários. Somente a cidade de Recife (PE) possui quatro centrais de atendimento com quase $20 \mathrm{mil}$ funcionários. A última unidade inaugurada na capital pernambucana é considerada a maior central de atendimento da América Latina, com 5,7 mil PAs e capacidade para 14 mil funcionários. A partir de 2010, a unidade passou a ser responsável por realizar mais de 17 milhões de contatos por mês, respondendo sozinha por $7 \%$ das interações (por telefone, e-mail, chat e $S M S$ ) efetuadas mensalmente pela Contax no território brasileiro.

As operações instaladas nos outros países da América do Sul representaram um aumento de 29\% da receita da empresa a partir do segundo trimestre de 2012 (CONTAX, 2013). A estratégia de atuação a partir da Colômbia e do Peru pode estar vinculada à intenção de prestar serviços para empresas norteamericanas que atendem clientes de língua hispânica (residentes nos Estados Unidos). Na Argentina, a empresa presta serviços domésticos e também para o Brasil, utilizando operadores brasileiros residentes naquele país.

\section{CONSIDERAÇÕES FINAIS}

A divisão territorial do trabalho das empresas analisadas demonstra como a desconcentração espacial das operações reflete a busca por "áreas desvalorizadas" (HARVEY, 2006b), onde além da disponibilidade de mão de obra barata, o Estado promove a instalação das redes necessárias aos fluxos corporativos. Como adverte o autor (Harvey, 2006 b, p. 125), a apropriação de um estoque de ativos desvalorizados (ou subvalorizados) viabiliza a destinação lucrativa dos excedentes de capital que não encontram as mesmas oportunidades em outros lugares.

A topologia das empresas Atento e Contax, demonstrou como entre as grandes corporações há uma tendência na última década de manutenção das unidades que prestam serviços mais complexos em áreas com maior "densidade informacional" (SANTOS, 1996), isto é, em pontos facilmente conectados com qualquer parte do globo. Enquanto as centrais de atendimento (unidades de operação) localizam-se, usualmente, em áreas desvalorizadas, onde os salários dos operadores são menores, as oportunidades de emprego são escassas e um grande contingente, especialmente, de mulheres jovens se submete às condições precárias de trabalho.

As tecnologias da informação permitem também a diversificação das atividades prestadas e o aprimoramento da relação com as empresas-clientes, com o objetivo de ampliação da acumulação. Nesse aspecto, foi salutar a análise das estratégias territoriais da "Empresa A", sobretudo, sua atuação direta na gestão dos negócios dos clientes e o fornecimento de infraestrutura de rede. Essas atividades são viabilizadas a partir da integração entre suas unidades - os datacenters, as fábricas de softwares e as centrais de atendimento -, distribuídas em pontos estratégicos do território.

Diante da análise das estratégias praticadas pelas empresas, constatamos que o uso das vantagens territoriais é desigual e está atrelado ao poder de cada agente. As grandes corporações impõem seu interesse aos territórios e, com o apoio do Estado, definem o traçado das redes geográficas que atendem às suas necessidades de fluidez. A ampliação da rede de fibra ótica no território brasileiro, por exemplo, tem respondido às demandas corporativas, enquanto a maior parte da população permanece na condição de exclusão digital.

A submissão dos lugares às divisões do trabalho particulares das empresas intensifica as disparidades territoriais. A restrição do acesso à informação é apenas uma das dimensões da desigualdade social e da exclusão que impede os indivíduos de uma vida mais justa. Como assevera Vainer (2007, p. 5), os processos de privatização de setores estratégicos, ao lado da ausência ou 
fragilidade de um projeto nacional, autoriza "o império de opções e decisões de empresas privadas, estas sim tornadas soberanas".

\section{REFERÊNCIAS}

ARRIGHI, G. O Longo Século XX. São Paulo: Unesp, 1996.

ARROYO, M. M. Dinâmica territorial, circulação e cidades médias. In: Eliseu Savério SPOSITO, E. S.; SPOSITO, M. E. B.; SOBARZO, O. (Org.) Cidades médias: produção do espaço urbano e regional. São Paulo: Expressão Popular, 2006, v. 1, p.71-85.

BENKO, G. A ciência regional. Oeiras, Portugal: Celta Editora, 1999.

CALLCENTER.INF.BR., 2013 Ir ou não para o interior? A decisão deve ser pautada pela diretriz estratégica da empresa. Disponível em: $<\mathrm{http}: / / \mathrm{www}$. callcenter.inf.br/outsourcing/51317/ir-ou-nao-para-ointerior/ler.aspx.> Acesso em: 22 Ago. 2013.

CASTILlO, R.; SILVA, A. B. da. Dinámicas metropolitanas en la era de la globalización: la promoción inmobiliaria para empresas en la ciudad de São Paulo, Brasil. In: Revista Eure (Vol. XXXIII, $\mathrm{N}^{\circ}$ 98), pp. 45-56, Santiago de Chile, maio, 2007.

CHESNAIS, F. A mundialização do capital. São Paulo: Xamã, 1996.

CONTAX. Relatório Anual, 2013. Disponível em: $<$ http://ri.contax.com.br/contax/web/arquivos/ Contax_RelAtividade_20120801_port.pdf.> Acesso em: 12 dez. 2012.

CORDEIRO, H. K. O centro da metrópole paulista. Expansão recente. São Paulo: Instituto de Geografia, Universidade de São Paulo, 1980.

DIAS, L. C. Redes: emergência e organização. In: CASTRO, I. E. et al. (orgs.). Geografia: conceitos e temas. Rio de Janeiro: Bertrand Brasil, pp. 141-162, 1995.
DIAS, L. C. Os sentidos da rede: notas para discussão. In: DIAS, L.; SILVEIRA, R. L. L. (orgs.). Redes, sociedades e territórios. Santa Cruz do Sul (RS): Edunisc, pp.11-28, 2005.

FIORI, J. L. 60 lições dos 90. Uma década de Neoliberalismo. São Paulo: Record, 2001.

HARVEY, D. "Do gerenciamento ao empresariamento: a transformação da administração urbana no capitalismo tardio". In: Espaço e Debates, ano XVI, n. 39, pp. 48-64, 1996.

HARVEY, D. Condição pós-moderna: uma pesquisa sobre as origens da mudança cultural. São Paulo: Edições Loyola, 2004.

HARVEY, D. The Limits to Capital. Londres: Verso, 2006a [1982].

HARVEY, D. A produção capitalista do espaço. São Paulo: Annablume, 2006b.

HARVEY, D. O novo Imperialismo. São Paulo: Edições Loyola, 2010.

HARVEY, D. Condição pós-moderna: Uma pesquisa sobre as origens da mudança cultural. São Paulo: Edições Loyola, 1996.

HIRST, P.; THOMPSON, G. Globalização em questão. Petrópolis: Vozes, 1998.

LENCIONI, S. Cisão territorial da indústria e integração regional no estado de São Paulo. In: M. F. Gonçalves et al. (orgs.). Regiões e cidades, cidades nas regiões: o desafio urbano-regional. São Paulo: UNESP/ANPUR, 2003.

LOJKINE, J. A Revolução Informacional. São Paulo: Cortez, 1995.

MINISTÉRIO DO TRABALHO E EMPREGO. Cadastro Geral de Empregados e Desempregados. Classificação Brasileira de Ocupações, Brasília, 2014. Disponível em: http://bi.mte.gov.br/bgcaged/ 
caged_acerto/caged_acerto_basico_tabela.php. Acesso em 12 outubro 2014.

NOREMBERG, M.; MÜLLER, R. Comparação do sistema VOIP e rede de telefonia fixa: Um estudo de análise de custo dos sistemas de VOIP e rede de telefonia fixa. 2011. Disponível em: <http:// baseinfortec.blogspot.com.br/2011/02/comparacaodo-sistema-voip-e-rede-de.html.>. Acesso em: 13 set. 2012.

PECK, J; TICKEL, A. Neoliberalizing Space. In: BRENNER, N.; THEODORE, N. Spaces of Neoliberalism: Urban Restructuring in North America an West Europe. Malden, USA: Blackwell Publishing, 2002.

PINHO, A. G.; VARGENS, J. R. (de) Regulation of VoIP in telecom industry. 2005. (Apresentação de Trabalho/Congresso).

SANTOS, M. A natureza do espaço: Técnica e tempo. Razão e emoção. São Paulo: Hucitec, 1996.

SANTOS, M. Por uma outra globalização: do pensamento único à consciência universal. Rio de Janeiro: Record, 2000.

SILVA NETO, J. B. Call Centers no Brasil: um estudo sobre emprego, estratégias e exportações. Dissertação (Mestrado em Economia). Universidade Federal de Uberlândia, 2005.

VAINER, C. Fragmentação e projeto nacional: desafios para o planejamento territorial. Anais: XII Encontro da Associação Nacional de Pós-Graduação e Pesquisa em Planejamento Urbano e Regional. Belém: ANPUR, 2007. 